\title{
The Learning Strategist Teaches First-Year Undergraduates:Embedding Learning Strategies and Metacognitive Dialogue into Course Content
}

\author{
Sharon Moukperian ${ }^{1}$, Vera Woloshyn,"* \\ ${ }^{1}$ Student Success Centre, Niagara College, St. Catharines, ON, Canada \\ ${ }^{2}$ Brock University, St. Catharines, ON, L2S 3A1, Canada \\ *Corresponding Author: vwoloshyn@brocku.ca
}

Copyright (C) 2013 Horizon Research Publishing All rights reserved.

\begin{abstract}
Using self-study methodology, we describe one professor's efforts to support students' academic learning by integrating three, evidence-based learning strategies and associated metacognitive dialogue about their use in a first-year, lecture-based course. Learning strategies included the activation/provision of prior knowledge, narratives and recursive question answering. Strategies were presented in an explicit format, with students provided with metacognitive information related to their use. Strategy use also was reinforced as part of an exam review. We advocate for the continued modeling and discussion of evidence-based learning strategies as part of undergraduate lectures while discussing limitations associated with the present study and directions for future research.
\end{abstract}

Keywords Learning Strategies, Metacognition, First-Year University

\section{Introduction}

Post-secondary institutions were established to provide in-depth knowledge related to specific academic disciplines $[1,2]$. Traditionally, this knowledge was delivered in a didactic lecture format or what is otherwise referred to as the "one-to-many model of transmission" or "instruction paradigm" [3] where the professor speaks and students listen. Relatively little attention was directed to exploring the quality of students' learning experiences or developing pedagogical approaches. This orientation has changed over time as many post-secondary institutions are challenged to retain students, with students citing learning obstacles as one reason for failure to complete their degree programs $[4,5]$. This paper will focus on one professor's efforts to support students' academic learning by integrating the use of three, evidence-based learning strategies and associated discussion about their use as part of a first-year,university course.

\section{Literature Review}

There is little debate that students must possess a repertoire of effective learning strategies and study skills in order to succeed in the post-secondary environment [6]. To this end, post-secondary institutions are required to provide direct learning services and accommodations to students with learning disabilities [7, 8]. For students without identified learning challenges, the predominant tendency has been to provide stand-alone workshops, seminars, and/or courses about reading, writing, and critical thinking at the post-secondary level[9], with researchers documenting some success with this latter approach.

For instance, Tinnesz, Ahuna, and Kiener[10] found that students who transferred strategies acquired as part of a methods-of-inquiry course to other courses experienced greater academic success relative to their peers who do not transfer these skills. Tinnesz and his colleagues qualified, however, that students needed to be self-motivated and metacognitively aware, knowing when and where to apply specific strategies across content areas. Unfortunately, most students rarely receive such metacognitive instruction as part of their post-secondary classes, with many instructors erroneously assuming that students possess and apply these strategies and skills routinely [11].

Many secondary-school students struggle with the transition to the post-secondary environment. These challenges, in part, reflect some students' preferences for passive learning environments that reduce learning to listening, note taking and regurgitation of critical information and concepts, as well as their tendency to value grades and products over the learning process $[12,13,14]$. Many students also find interpreting professors' expectations, employing time management skills, and managing increasingly difficult learning concepts to be challenging [15]. Finally, it is often difficult to persuade older students to employ learning strategies that require them to regulate, evaluate, and monitor their cognitive processes [12]. 
Over three decades of research demonstrates that providing younger students' with explicit instruction facilitates their learning $[6,16]$. Explicit instruction involves frequent modeling of strategies and the provision of metacognitive information about the parameters associated with their use (i.e., "why, "when", and "where"). The modeling process includes the verbalization of thought processes while using strategies and the affirmation of the cognitive effort expended while processing text [17].Such instruction can facilitate students' overall understanding or knowledge of the learning process, as well as their ability to monitor, control and adjust their cognitive processing in order to complete tasks successfully while completing specific tasks as well as their ability to monitortheir success completing it - processes that collectively form metacognitive awareness $[18,19]$

There is relatively little research, however, exploring the provision of explicit instruction in the post-secondary classroom. Furthermore, these seemingly sophisticated learners often do not engage in, and often are unaware of, evidence-based learning processes $[20,21]$. Thus, we like others [6] believe that providing post-secondary students with explicit strategy instruction during subject-specific lectures will increase their awareness of metacognitive processes and enhance their self-regulation, motivation, and engagement in learning. However, we also acknowledge that such instruction is time-consuming, difficult to implement in large classes, and unfamiliar to most professors.

We are two female instructors that share common interests in strategic instruction and student learning at the post-secondary level. The first author and course instructor is a learning strategist at a local college (predominately granting 2-year diplomas), providing one-on-one instructional support to students with learning disabilities. At the time of this study, she also was a part-time instructor and doctoral student at the university where the second author is employed. The second author's research interests include developing and implementing strategic instruction and teacher professional development. In this study, we describe the first author's efforts to provide targeted instruction in generalizable learning strategies within the context of a subject-specific, first-year, lecture-based course.

\section{Research Methodology}

We adopted self-study methodology that was autobiographical in nature and included collaboration with a colleague [22]. When colleagues share critical conversations about practice and offer insights into experiences, new possibilities for practice emerge andprofessional knowledge and expertise can be developed [23, 22].

\subsection{Instructional Context}

The course described here is a required one for education students enrolled at a medium-sized university located in
Ontario, Canada. Students typically complete this course in their first year or second year of studies, with approximately 200-250 students enrolled in each of two sections. The course is intended to provide students with an overview of the historical, sociological, psychological and philosophical foundations of education. The History of Education unit was the initial module, consisting of six, two-hour weekly lectures with an accompanying one-hour tutorial. Module content included the origins of formal schooling, the changing image of the learner, the history of technological innovations in education, the history of alternative education and the historical and contemporary criticisms of public schools. Students were encouraged to use critical instances in educational history when considering contemporary educational debates.

\subsection{Learning Strategies}

Three learning strategies formed the foundation of the instruction provided here: prior knowledge activation/provision, narratives and recursive question answering. In part, these strategies were selected as a result of the substantial literature reflecting their effectiveness as learning tools as well as their general applicability across many subject areas within the social sciences, humanities and education [6]. Prior knowledge has been identified as the single most important factor to influence learning [24, 25]. When students possess prior knowledge that is consistent with to-be-learned information, the learning process is enhanced. Instructing students to activate relevant prior knowledge when processing information (through questioning or prediction), or providing them with such relevant information (through verbal explanation, text or images/video), enhances their understanding and retention of new information $[25,26]$.

Narratives, or what are commonly referred to as stories, can provide powerful learning tools by providing students with a mechanism for encoding and retrieving factual information. When expository content is presented through narratives, students become engaged emotionally and cognitively with the content, thereby increasing their retention of this information [27, 28]. Thus, supplementing expository information through the presentation of accompany complementary narratives is an effective instructional technique.

The processes of questioning and question-answering can also prompt learners to activate prior knowledge, thus rendering new information sensible, comprehensible, and memorable. When students are providedwith higher-level thinking questions, newinformation is organized in a meaningful manner and their understanding and recall is enhanced [29-31].

Recursive question answering involves having studentsuse their prior knowledge to respond to open-ended questions. These questions are then extended slightly, requiring students to clarify their initial responses. This 
questioning method provides students with a venue for clarifying and exploring ideas, searching for missing information and expanding perceptions [32].

\subsection{Instructor Beliefs}

Having taught this course before as a part-time instructor and being employed as a full-time learning strategist at a local college, the instructor was firm in her belief that she wanted to "do more" for students than provide them with content knowledge. She acknowledged the influences of information processing theory, experiential learning and emotional engagement in her teaching and work as a strategist, "how can I teach so that I do not overload students when they have to learn new information...dealing with that emotional piece that is so important to getting them engaged" (Interview).

\subsection{Data Collection and Analysis}

The researchers communicated regularly throughout the duration of the six-week course, with the first author sharing her instructional approaches and the second author responding with critical questions and considerations for subsequent instruction. Most relevant to the descriptive case study here, these dialogues focused on the rationale underlying instructional approaches and how to facilitate students' metacognitive awareness of these learning methods and promote their transfer and generalization.

Data collection included lecture materials and power point presentations, instructor's teaching reflections, and an open-ended interview with the instructor that was audio recorded and transcribed for subsequent analysis. Data analysis consisted of reading and re-reading the lecture materials, teaching reflections and interview transcription in order to develop a holistic understanding of the integrated delivery of learning strategies as part of course content [32, 34]. After reviewing the data independently, the researchers met to present their interpretations and arrive at a shared understanding of the themes and associated conclusions, with these discussions and reflections continuing throughout the writing of this article

In this paper, we describe instructional practices related to prior knowledge activation/provision, narratives, recursive question answering and an integrated, strategic exam review. Specifically, we outline how these learning strategies were integrated into instruction, addressing associated challenges and instructional solutions. We also recognize the interchange between these strategies, acknowledging that use in one often complements and facilitates instruction in the others.

\section{Prior Knowledge Activation /Provision}

Prior knowledge activation constituted a primary instructional strategy. Typically, this process involved having students respond to targeted questions related to their own experiences (e.g., What was your experience with...? What is your memory of ....?). Other questions involved having students make predictions and consider the nature of schooling (e.g., What do you think would happen if...? What is your vision of....? What do you want to happen in the future with respect to...?).

In order to teach the historical concept of 'child', I had students activate their prior knowledge. 'What was your experience as a child in context of your family, school and community?' The students created a definition of child based on these experiences. We deconstructed their definitions in terms of the influences of society, education, and family. This prepared them to analyze various course materials through these specific lenses. (Lecture, 3 )

When it was suspected that students did not possess relevant prior knowledge, it was provided to them. The most frequent method involved providing them with visuals in the form of videos and/or pictorial images.

I'm thinking to myself... they [students] don't know what it's like in the Industrial Era, the turn of the century. They don't know what it's like in the Romantic Period because that's what I'm teaching, about what children were like, what was the environment like. I tried to find video clips, YouTube clips, or a collage ofpictures to give them a sense of what the kids looked like, what society looked like... Everybody sitting in rows...Everybody dressed the same... All the suits were the same. The ties were the same. I thought that was relevant to bring that period alive to them so that when they're reading they can say okay, I can 'see' what it looked like and use that knowledge when we talk about reconstructing our culture or cultural continuance. (Interview)

These materials were used to help students create a sense of context of time and place. Students were then directed to draw upon this context when recalling material.

Telling them that they can then retrieve this information by remembering the video, by remembering the music so they can pair that with the content. (Interview)

In addition to providing context and background knowledge, many of these visuals were selected on the basis that they would solicit an emotional response from students "By activating more senses and engaging the emotions, I believed that this concept would be retained in long-term memory" (Teaching Reflections, Lesson 2).

In one class, students were presented with a government newsreel produced in the 1950s testifying to the success of residential schools for Aboriginal children (www.youtube.com\%2fwatch\%3fv\%3ds_V4d7sXoqU) after being informed that they would be watching a video of an "exemplary" model of schooling. The clip portrayed Aboriginal children dressed and groomed in European fashion (e.g., school uniforms, boys with short hair, girls with barrettes), playing games such as jump rope and hockey. Students were challenged to consider whether this was exemplary schooling and the experiences of children in these 
classrooms. They also were challenged to consider their emotional response to the video (e.g., shock, anger, surprise, disappointment).

After responding to these questions and/or reviewing provided materials, students were informed about the importance of activating relevant prior knowledge prior to engaging with lecture materials. Specifically, they were told that reconsidering their verbal and emotional responses to these questions and/or visuals would assist them derive meaning from lecture content and recall it subsequently.

\section{Narratives}

The instructor developed narratives to assist students' to process and retrieve information.

In lecture, I am presenting new information that the students may nothave prior experience or knowledge of, and this can create memory overload, especially when working with complex theories or concepts... The question I ask myself is how I can connect these abstract concepts to something that is meaningful to my students? If I can use narrative to place the concepts within a story format, then the students can retell the story to try and retrieve the information connected with the story. (Teaching Reflections, Lesson 1)

Aware that many students often question the value of studying history believing that past events have little relevance to current events and wanting to validate course content stipulating ethics as a vital part of the school curriculum (e.g., Plato's emphasis on character development), she presented students with the self-authored narrative entitled, "Tale of Two Greedies" (adopted from $A$ Tale of Two Cities by Charles Dickens). The narratives, complete with instructor-generated visuals, drew a parallel between John Law's creation of the European banking system (1700s) and the 2008 financial crisis. In both situations, investors initially enjoyed large returns on their investments prior to the collapse of systems. Prior to reading the narrative, students brainstormed events related to the 2008 economic crisis. They were also provided with a public statement that teachers and the education system were to "blame" for the 2008 financial crisis as they had not provided adequate moral development to students who were now adults holding positions of influence and power. This statement was intended to elicit a strong emotional response in students (who were intending to become educators)thus increasing their engagement and attention to the narratives.

The idea of ethical education and the importance of teaching ethics was not loss on the Greeks...but it has been loss today... let me tell you a story using the backdrop of the story framework of a Tale of Two Cities

We have the society of 2007-2009 and the society of the 1700 s

Meet John Law [draw man in KILT] and the Investment bankers of America [draw man in green with dollar sign for body]
John Law is a Scotsman is interested in starting a Bank ... a new concept for the 1700 s....in Scotland they didn't like the idea [they are very thrrrrrriffffty] but in France he was responsible for helping get the King of France out of debt.... Law was able to establish a bank with paper currencyand there was a $40 \%$ return on the investment... what would people do? [draw a line between the two eras].

In Americathe land of opportunity there were people willing to give out money to whoever to buy houseswith little or no down payment life was goodbuying houses were happy the builders andrealtors were happy...the investment bankers were REALLY HAPPY [draw $\$ \$ \$ \$ \$ \$ \$ \$ \$ \$$ ]

HOWEVER, there was a small problem. (Lecture Notes, Session 5, captions and spellings in original, drawings in italics)

After responding to the narrative, the first author shared her rationale for using the story as an instructional tool. She explained, "telling the story and using a different medium for presenting the content, as a 'tale' it would be memorable and readily recalled. Using emotion (the accusation that teachers are to blame) could also be helpful as a trigger for memory" (Interview).

\section{Recursive Questioning}

Another focal instructional strategy involved responding to recursive questions generated from open-ended question stems. The instructor identified using approximately one-half dozen primary stems including, What is/are...?, What does...? How do...?, How is ....related towhat we studied earlier? What does it look like? Sound like? Feel like, and Why is...?

As part of the introductory lecture, students were directed to draw upon their own experiences to define "education", "What does it look like? What does it feel like" What does it sound like?" They were directed to envision themselves as educators and discuss the following prompt, "What do you want your students to look like, sound like, and remember from their formal education in your classrooms?" (Lecture 1)

My focus was to engage students emotionally...I used recursive questions, which is a counseling technique [33] where you ask the same type of questions again and again like peeling an onion to take off layers. You ask a question and you get the outermost layer. Instead of just being satisfied with that, you ask it again and you get the next layer. You keep doing that until there is no more onion or it becomes clear what is inside. I wanted the students to start to think concretely. I wanted them to make an abstract term like "education" tangible using recursive questions such as, What does it look like? Sound like? Feel like? (Teaching Reflections, Lesson 2)

As a follow up to watching the Canadian Residential School Propaganda video, students were asked to consider and discuss, 'what the schools system looked like, felt like, and sounded like for these children?' The instructor then modeled how they could respond to questions related to key 
lecture terminology, "I demonstrated how to take that information and make it more personal...to have a mental dialogue with the words so that there is a connection by using questions. I modeled the first question, then we did the next two together." (Teaching Reflections, Lesson 2)

What we have here are words on a page and these words may not mean much to us at this time. We need to ask ourselves questions in order to create meaning and later on use these questions to retrieve the information from memory. Look at the phrase, 'cultural transference as key to sustaining societies across generations'. Let me tell you how I would answer the first question, 'What is cultural transference? In order to answer this question I need to identify what is culture. For me, culture is a group of practices, rules, group beliefs etc.... Now, I need to consider what is transference. For me, transference involves sharing group beliefs and values among generations. So combining these two pieces of information, cultural transference reflects how culture will be transferred to young children... Now that I know this term, the next question is, 'What is an example of how a culture is transferred?' (Lecture 2)

In another lecture, students were asked to consider the following questions (developed using generic question stems) after exploring the role and evolution of technology in the classroom:

How do schools play catch up with society?

How have instructional innovations improved teaching and learning?

How do teachers use their knowledge of technology to leverage instructional technologies in the classroom?

Why have low technical instructional tools (e.g., blackboards) persisted for so long?

What technologies do you see that are still being used in schools today?

'Each medium (e.g. camera, tape recorder) mediates experience through its own lens.' What does this mean?

What technological issues are still relevant today?

(Lecture 4)

Especially important, the instructor questioned the students about her repeated use of questions throughout the lectures, "Why do I keep modeling these questions? Why do I keep repeating these questions as a technique? Have you ever asked yourself this?" She then provided a rationale for her instructional approach.

'I keep using these questions to stimulate your thinking. We have used them in past lectures to help create meaning and I have mentioned that they will help your recall information from memory. I keep repeating myself because I want you to use these questions on your own when approaching new material.' (Lecture 4)

\section{Exam Preparation}

The second half of the final lecture was designated for preparation for the final exam. However, rather than provide students with details related to content that would be contained in the exam, Sharon used this session as an opportunity to demonstrate and reinforce the use of the specific learning strategies integrated throughout the lectures as study tools. Specifically she provided them with critical questions (about 10-15 from each session) related to lecture content. She then modeled the use of a metacognitive strategy (referred to as the stop light technique) designed to assist students to use their study time efficiently (i.e., devoting less time to information that they knew well and greater time to information that was less familiar).

For the exam review, I explicitly taught the students how to use a strategy that I developed called the 'stop light technique' (Figure 1) to figure out what information was easy or well known (green), weak (yellow) and difficult or not known well (red). This is a colour-coding system that allows students to use coloured markers on their reading/lecture/study materials, so when they study, they know where to focus their time and energy. (Teaching Reflections, Lesson 6)

\section{Stop Light Strategy}
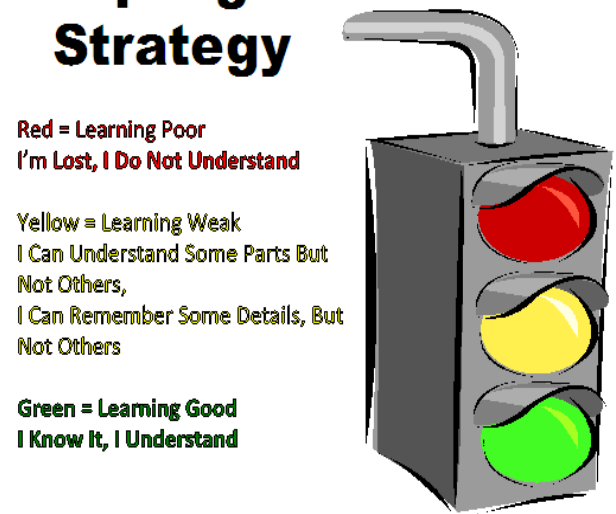

Figure 1. Stop Light Strategy® Moukperian, 2006

The instructor also recognized that students needed to evaluate whether they could respond accurately to the review questions in order to use these tools effectively. She therefore created a graphic organizer outlining criteria that demonstrated various levels of learning.

In order to identify what is difficult to learn, I asked them 'How do you know that you know?' Then, using a graphic organizer, I operationalized "knowing" as the

1) ability to name a term/concept/theory,

2) define that term/concept/theory,

3) provide a real life example and

4) form a mental representation or picture of that term/concept/theory.

She then modeled the process of using these two tools when responding to the review questions associated with the first two lectures/sessions (Figure 2). She explained that the review questions reflected the recursive, open-ended questions discussed during lecture (e.g., What is/are...?, 
What does...?How do...?, How is ....related to what we studied earlier?)

When I did the review, I modeled for them how they could study... There were specific question stems related to the course material, so I went through and generated these. [I told students] here's how I would study. And I generated these questions based on the slides that were in Lectures/Sessions 1 and 2 and I picked out the key points, there were maybe 10-12 questions. And then I showed them the power point lecture slides where I've pulled the questions. (Interview)

So I went through why I did this. I said this is my red. When I have something that's a red, I'm going to take the time to go through and put this much time into understanding that concept. (Interview)

\section{Who is Plato? \\ What topics were important to Plato and why? \\ What is the definition of education? \\ Why do we have schools/What were the reasons \\ for their development? \\ What are the altematives to formal education? \\ List 3 \\ Why did schools assume new importance in the $19^{\text {th }}$ Century? What was the focus of govemment during this period?}

Figure 2. Exemplar instructor-generated review questions for lectures 1-2

The instructor then modeled how she could use the graphic organizer to focus on "red stop light" questions (e.g., Question \#6 as illustrated in Figure 3)

\section{Who is Plato? \\ What topics were important to Plato? Why? O \\ What is the definition of education? 0 \\ Why do we have schools/What were the reasons for their development? \\ What are the altematives to formal education? \\ List 3 \\ Why did schools assume new importance in the $19^{\text {th }}$ Century? 0}

Figure 3. Application of stop light strategy for lectures $1 \& 2$

The instructor explained how that using the graphic organizer could help them prepare for different formats of examination questions including multiple choice (greater focus on naming and defining columns) and essays (greater focus on examples and mental representations columns, Figure 4, Images retrieved fromhttp://bit.ly/13xXMGd and http://bit.ly/13kWumcrespectively).

We then went on to how I can use a graphic organizer to study. And in this case, we used the lecture on cultural continuance [Lecture 2].

We need to recognize the textbook definition if it's in a multiple-choice question. What we're going to recognize are some key terms that might click in our memory. Now if it's an essay, I need a real life example, so we watched a video and talked about residential schools and how they were used to keep the culture the same. So in the first nations, people lost their identity, their language etc... (Lecture, 2)

\begin{tabular}{|c|c|c|c|c|}
\hline TERM / CONCEPT & DEFINIIION & $\begin{array}{l}\text { KEY VOCAB } \\
\text { WORDS }\end{array}$ & $\begin{array}{l}\text { REAL LIFE } \\
\text { EXAMPLE }\end{array}$ & PICTURE \\
\hline $\begin{array}{l}\text { Cultural } \\
\text { Continuance }\end{array}$ & $\begin{array}{l}\text { - Transfers cultural } \\
\text { knowledge, skills, and } \\
\text { values to the next } \\
\text { generation \& } \\
\text { newcomers } \\
\text { - Inducts children } \\
\text { into societal norms } \\
\text { - Emahosizes } \\
\text { tradition and } \\
\text { nationalism } \\
\text { - Posits the non- } \\
\text { critical acquisition of } \\
\text { a core curriculum }\end{array}$ & $\begin{array}{l}\text { Transfers, inducts, } \\
\text { tradition, nationalism, } \\
\text { STABILTY }\end{array}$ & $\begin{array}{l}\text { RESIDENTIAL } \\
\text { SCHOOLS } \\
\text { To keep a culture } \\
\text { stable and to make } \\
\text { sure children adopt } \\
\text { the values and learn } \\
\text { the importance of } \\
\text { loyalty to the country } \\
\text { - schools have the } \\
\text { job of teaching/ } \\
\text { instilling these values } \\
\text { and vocabulary }\end{array}$ & \\
\hline $\begin{array}{l}\text { Cultural } \\
\text { Reconstruction }\end{array}$ & & $\begin{array}{l}\text { Evolving, innovating, } \\
\text { constructing } \\
\text { PROGRESSIVE }\end{array}$ & $\begin{array}{l}\text { Factory child - } \\
\text { industrial revolution }\end{array}$ & \\
\hline $\begin{array}{l}\text { Self- } \\
\text { Development }\end{array}$ & & & & \\
\hline
\end{tabular}

Figure 4. Example of study organizer for "red" stoplight concepts

The instructor explained that by provided an 'untraditional' review where students were guided in how to consider how they encoded lecture materials and reflect on the familiarity of lecture content, they would be well prepared to study for the final examination independently.

So I'm hoping that by modeling how to study for my exam... by doing all that work generating the questions... by telling them here are good questions to generate and how to study for these questions ....I'm not going to see them [during office hours prior to the examination]. (Interview)

\section{Discussion}

The findings from this study add to the existing literature related to the importance of providing students with strategic instruction $[6,35]$. Specifically, this study documents one instructor's efforts to activate students' relevant prior knowledge (or provide such background knowledge when necessary), generate narratives for course materials and use recursive, question- answering while lecturing. Equally important, are the instructor's efforts to inform students of the use of these learning strategies as part of her instructional methods - a critical component of explicit instruction and the factor that separates the type of the instruction provided here from that usually found in lectures. Indeed, it is these types of dialogues promote learners' metacognitive development and increases their likelihood of transferring and generalizing strategic processes across varied learning contexts.

We acknowledge the limitations associated with this study, notably that only the instructor's experiences and perceptions are reported here. Students' voices and 
experiences are needed to provide credibility to the instructional methods employed here and validate their effectiveness as learning aids. We also acknowledge that the instructor's role as a learning strategist and her communications with an informed colleague placed her in a position of advantage, providing her with extensive knowledge and resources with respect to using explicit instruction and guiding students in the use of evidence-based learning strategies. We realize that such expertise and resources are not part of the training of most post-secondary instructors nor are they part of their ongoing educational development activities.

\section{Conclusion}

In conclusion, we advocate for the greater use of strategic instruction as part of large, lecture-based classes, especially when working with first-year students who are most likely to struggle with the transition from secondary to post-secondary learning environments. We recommend the use learning strategies that can be readily transferred across subject areas (like the ones reported here), acknowledging that providing students with systematic metacognitive information (how, when, why and where) is vital for such generalization. Finally, we are optimistic about the potential of this format of instruction as part of smaller seminar-based classes (complementing larger lecture-based instruction), acknowledging however, that seminar leaders would require educational development in the implementation of explicit instruction and evidence-based learning strategies. We argue that students should be provided with structured opportunities to generate and personalize targeted learning strategies (e.g., using generic question stems to generate potential examination questions, developing personal narratives as lecture summaries). We acknowledge the constraints associated with large-class sizes and voluminous course content, but believe that instructors must be willing to engage in some compromise between information transmission and the modeling of strategic cognitive processes in order to maximize student learning.

\section{REFERENCES}

[1] P. Axelrod. The Promise of Schooling (pp. 83-103). Toronto: University of Toronto Press, 1997.

[2] T. Wotherspoon. The Sociology of Education in Canada. Toronto: Oxford University Press, 2009.

[3] B. Barr, J. Tagg. From teaching to learning: A new paradigm for undergraduate education. Change, Vol.27, No.6, 12-25, 1995.

[4] M. D. Dooley, A. A. Payne, L. A. Robb, Understanding the Determinants of Persistence and Academic Success in University: An Exploration of Data from Four Ontario Universities, (pp. 5-45). Toronto: Higher Education Quality
Council of Ontario, 2011.

[5] R. Finnie, A. Sweetman, A Usher. A Framework for Thinking about Participation in Post-secondary Education. In R. Finnie, A Sweetman, \& A. Usher, (Eds). Who goes? Who stays? What matters? Accessing and Persisting in Post-secondary Education in Canada, (pp.1-30). Montreal: McGill-Queen's University Press, 2008.

[6] R. F. Flippo, D. C. Caverly. (Eds.). Handbook of College Reading and Study Strategy Research. 2nd Edition. New York, NY: Routledge, 2009.

[7] Americans with Disability Act, Section 504, (14). Retrieved from www.eric.ed.gov.

[8] Ontario Human Rights Code Retrieved from http://www.elaws.gov.on.ca/html/statutes/english/elaws statutes $90 \mathrm{~h} 19$ e.htm, 2008.

[9] M. P. Ryan, P. A. Glen. What do first year students need most: Learning strategies instruction or academic socialization? Journal of College Reading and Learning, Vol.34, 4-28, 2004.

[10] C. G. Tinnesz, K. H., Ahuna, M. Kiener. Toward college success: Internalizing active and dynamic strategies. College Teaching, Vol.54, No.4, 302-306, 2006.

[11] P.A. Alexander, E. Fox. Adolescents as Readers. In M.L. Kamil, P.D. Pearson, E.B. Moje, \& P.P. Afflerbach (Eds.), Handbook of Reading Research Vol.I (pp. 157-176). New York: Routledge, 2011.

[12] M. C. Alvarez, V. J. Risko. Motivation and Study Strategies. In R. F. Flippo, \& D. C. Caverly (Eds.), Handbook of College Reading and Study Strategy Research. 2nd Edition (pp. 199-219). New York, NY: Routledge, 2009.

[13] V. C. Smith, L. A. Cardaciotto. Is active learning like broccoli? Student perceptions of active learning in large lecture classes. Journal of the Scholarship of Teaching and Learning, Vol.11, No.1, 53-61, 2011.

[14] K. Struyven, F. Dochy, S. Janssens. Students' likes and dislikes regarding student-activating and lecture-based educational settings: Consequences for students' perceptions of the learning environment, student learning and performance. European Journal of Psychology of Education, Vol.23, No.3, 295-317, 2008.

[15] E. B. Moje, D. Stockdill, K. Kim, H. Kim. The Role of Text in Disciplinary Learning. In M.L. Kamil, P.D. Pearson, E.B. Moje, \& P.P. Afflerbach (Eds.), Handbook of Reading Research Vol. IV, (pp. 453-486). New York, NY: Routledge, 2011.

[16] M., Pressley, V.E. Woloshyn (Eds.), Cognitive Strategy Instruction that Really Improves Children's Academic Performance. Cambridge MA: Brookline Books, 1995.

[17] V.E. Woloshyn, A. Elliott, S. Kaucho. (2001). So what exactly is explicit strategy instruction? A review of eight critical teaching steps. The Reading Professor, Vol.24, No.1, 66-114, 2001.

[18] J. Hattie, H. Timperley. The power of feedback. Review of Educational Research, Vol.77, 81-112, 2007.

[19] P.H. Winne. A metacognitive view of individual differences in self-regulated learning. Learning and Individual 
Differences, Vol.8, 327-353, 1995.

[20] P.H. Winne, D.L. Jamieson-Noel. Exploring students' calibration of self-reports about study tactics and achievement. Contemporary Educational Psychology, Vol.27, 551-572, 2002.

[21] P.H. Winne, D.L. Jamieson-Noel. Self-regulated studying by objectives for learning: Students' reports compared to a model. Contemporary Educational Psychology, Vol.28, 259-276, 2003.

[22] S. Pinnegar, M. L. Hamilton. Self-study of practice as a genre of qualitative research theory, methodology, and practice. Self Study of Teaching and Teacher Education Practices, Vol.8, Sense Publications, 2009.

[23] S. Brookfield. Becoming a Critically Reflective Teacher, San Francisco: Jossey Bass. 1995.

[24] D. P. Ausubel. The use of advance organizers in the learning and retention of meaningful verbal material, Journal of Educational Psychology, Vol.51, 267-272, 1960.

[25] P. I. Mulcachy-Ernt, D. C. Caverly. Strategic Study-Reading. In R. F. Flippo, \& D. C. Caverly (Eds.), Handbook of College Reading and Study Strategy Research. 2nd Edition. (pp. 177-198). New York, NY: Routledge, 2009.

[26] B. Mitra, J. Lewin-Jones, H. Barrett, S. Williamson. The use of video to enable deep learning. Research in Post-Compulsory Education, Vol.15 No.4, 405-414, 2010.

[27] A. S. Janit, G. S. Hammock, D. S. Richardson. The power of fiction: Reading stories in abnormal psychology. International Journal for the Scholarship of Teaching and
Learning, Vol.5, No.1, 1-14, 2011.

[28] M. B. Wolfe, J. A. Mienko. Learning and memory of factual content from narrative and expository text. British Journal of Educational Psychology, Vol.77, 541-564, 2007.

[29] T. Brothen, C. Wamback. Using factual study questions to guide reading and promote mastery learning by developmental students in an introductory psychology course. Journal of College Reading \& Learning, Vol.30 No.2, 158-166, 2000.

[30] T. G. Devine, J. S. Kania. Studying: Skills, Strategies and Systems. In J. Flood, D. Lapp \& J.R. Squire (Eds.), Handbook on Research on Teaching the English Language Arts. 2nd Edition, (pp. 942-954). Mahwah, NJ: Erlbaum, 2003.

[31] G. Phillips. Using open-book tests to strengthen the study skills of community-college biology students. Journal of Adolescent \& Adult Literacy, Vol.49, No.7, 574-582, 2006.

[32] J. W. Creswell. Educational Research: Planning, Conducting, and Evaluating Quantitative and Qualitative Research, 4th Edition. Boston, MA: Pearson Education, 2012.

[33] G. Egan. The Skilled Helper, 7th Edition, (pp.51-65). Pacific Grove, CA: Brooks/Cole, 2002.

[34] S. B. Merriam. Qualitative Research in Practice: Examples for Discussion and Analysis. San Francisco: Jossey-Bass, 2002.

[35] B. D. Karge, K. M. Phillips, T. Jessee, M. McCabe. Effective strategies for engaging adult learners. Journal of College Teaching \& Learning, Vol. 8 No.12, 53-56, 200 